\title{
Controls on the transport of oceanic heat to Kangerdlugssuaq Glacier, East Greenland
}

\author{
TOM COWTON, ${ }^{1,2}$ ANDREW SOLE ${ }^{3}$ PETER NIENOW, ${ }^{1}$ DONALD SLATER, ${ }^{1}$ \\ DAVID WILTON, ${ }^{3}$ EDWARD HANNA ${ }^{3}$ \\ ${ }^{1}$ School of Geosciences, University of Edinburgh, Drummond Street, Edinburgh, EH10 4ET, UK \\ ${ }^{2}$ Department of Geography and Sustainable Development, University of St Andrews, St Andrews, KY16 9AL, UK \\ ${ }^{3}$ Department of Geography, University of Sheffield, Winter Street, Sheffield, S10 2TN, UK \\ Correspondence Tom Cowton <tom.cowton@st-andrews.ac.uk>
}

\begin{abstract}
Greenland's marine-terminating glaciers may be sensitive to oceanic heat, but the fjord processes controlling delivery of this heat to glacier termini remain poorly constrained. Here we use a threedimensional numerical model of Kangerdlugssuaq Fjord, East Greenland, to examine controls on fjord/ shelf exchange. We find that shelf-forced intermediary circulation can replace up to $\sim 25 \%$ of the fjord volume with shelf waters within $10 \mathrm{~d}$, while buoyancy-driven circulation (forced by subglacial runoff from marine-terminating glaciers) exchanges $\sim 10 \%$ of the fjord volume over a $10 \mathrm{~d}$ period under typical summer conditions. However, while the intermediary circulation generates higher exchange rates between the fjord and shelf, the buoyancy-driven circulation is consistent over time hence more efficient at transporting water along the full length of the fjord. We thus find that buoyancy-driven circulation is the primary conveyor of oceanic heat to glaciers during the melt season. Intermediary circulation will however dominate during winter unless there is sufficient input of fresh water from subglacial melting. Our findings suggest that increasing shelf water temperatures and stronger buoyancy-driven circulation caused the heat available for melting at Kangerdlugssuaq Glacier to increase by $\sim 50 \%$ between 1993-2001 and 2002-11, broadly coincident with the onset of rapid retreat at this glacier.
\end{abstract}

KEYWORDS: arctic glaciology, calving, glacier discharge, ice/ocean interactions

\section{INTRODUCTION}

Many of Greenland's marine-terminating outlet glaciers underwent a phase of rapid retreat and acceleration in the late 1990s and early 2000s (Rignot and Kanagaratnam, 2006), with the consequent discharge of ice into the ocean responsible for $58 \%$ of total mass loss from the ice sheet over the period 2000-05 (Enderlin and others, 2014). This retreat was coincident with a period of ocean warming around Greenland (e.g. Hanna and others, 2009; Rignot and others, 2012), leading to suggestions that retreat may have been triggered by increased submarine melting at the calving fronts of marine-terminating glaciers (e.g. Straneo and Heimbach, 2013). These glaciers are however typically separated from the shelf by long, narrow fjords, which modulate the delivery of oceanic heat to the ice-sheet margins (Straneo and Cenedese, 2015). Until the processes controlling fjord circulation are better understood and quantified, the timescales on which marine-terminating outlet glaciers may be sensitive to variability in ocean temperature remain difficult to assess. A lack of understanding of fjord processes also hinders our ability to quantify the exchange of heat and fresh water between the ocean and the ice sheet, and to predict how this exchange will evolve as the climate warms.

Two mechanisms have been proposed as the primary drivers of exchange between the fjord and shelf, and thereby delivery of oceanic heat to glacier termini (e.g. Straneo and Cenedese, 2015). In the first mechanism (intermediary circulation), the exchange is driven by density gradients, which form between the fjord and shelf as a result of variability in shelf water properties, particularly during the passage of coastal storms (e.g. Arneborg, 2004; Jackson and others, 2014). In the second mechanism (buoyancy-driven circulation), the input to the fjord of meltwater runoff (and to a lesser extent fresh water from submarine melt) from glaciers drives exchange. The relative efficacy of these processes, and how they may differ between fjords and over time, remains poorly understood (Straneo and others, 2013).

While field observations are critical for understanding the circulation of water in Greenland's fjords, obtaining the required measurements is extremely challenging because of the remote locations and hazardous conditions (Straneo and others, 2013). Observations from within several kilometres of glacier calving fronts, key to elucidating the interaction of the ice sheet and ocean, are especially sparse. Interpretation of field measurements is also hindered by the need to separate the integrated influences of competing forcing mechanisms, and the aliasing of spatial and temporal variability in water properties over the course of surveys (e.g. Sutherland and Straneo, 2012; Sutherland and others, 2014).

Numerical models provide a complementary approach to studying fjord circulation, permitting the effects of competing forcings to be isolated (e.g. Sciascia and others, 2014; Carroll and others, 2015; Gladish and others, 2015). In this paper, we use a three-dimensional (3-D) numerical model of Kangerdlugssuaq Fjord (KF), a large, deep-silled fjord in southeast Greenland (Fig. 1a), to (i) characterise and quantify the exchange of water between the fjord and shelf associated with intermediary and buoyancy-driven circulation in the fjord, (ii) assess the relative efficacy of the two forms of circulation as mechanisms of fjord renewal and (iii) quantify the 

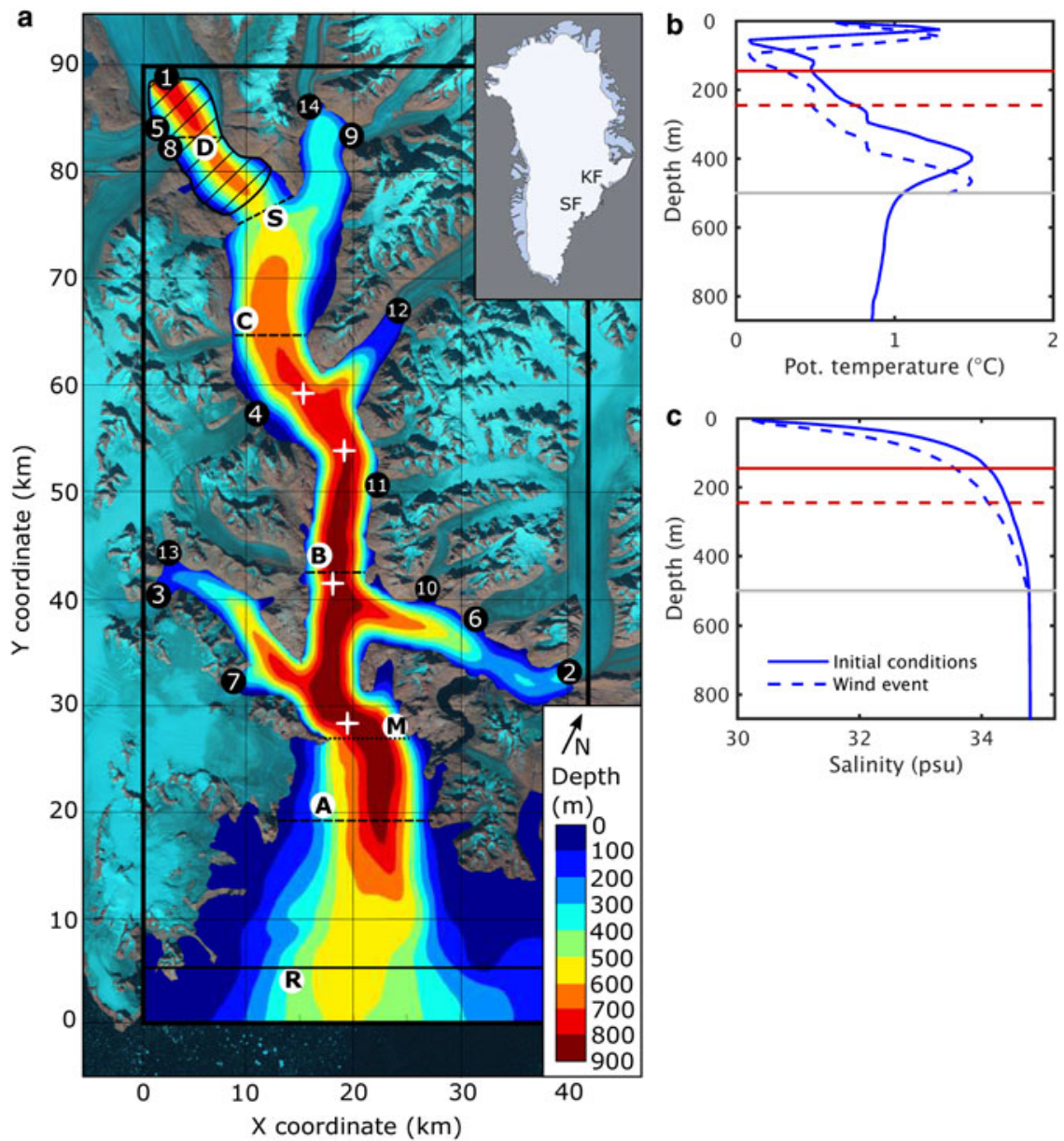

Fig. 1. Model set up. (a) Landsat ETM+ image of KF (16 August 2002), overlain with fjord bathymetry (Syvitski and others, 1996; Dowdeswell, 2004). The box denotes the extent of the model domain. Black circles mark the glaciers from which runoff is input to the modelled fjord, with the numbers showing catchment rank in terms of runoff. The largest, KG, is number 1 . Hatching denotes the area commonly choked by ice mélange resulting from calving by this glacier. The dotted line $(M)$ marks the fjord mouth section used to calculate transport into and out of the fjord, while dashed lines show sections A-C, chosen to correspond with Sutherland and others (2014), and section D towards the fjord head. S marks the section across the inner sill, and solid line R marks the extent of the relaxation zone at the southern boundary. White crosses show the location of four CTD stations, averaged to give the temperature and salinity profiles shown in $(b-c)$. Inset shows the location of KF and SF in Greenland. (b-c) Initial conditions for (b) potential temperature and (c) salinity used in all experiments (solid blue lines) and an example of the modified stratification (dashed blue lines) applied on the shelf to simulate wind events in some experiments $\left(\Delta h_{i}=100 \mathrm{~m}\right.$, see Section 3.4.1). Also shown is the depth of the $\sigma_{\theta}=27.3 \mathrm{~kg} \mathrm{~m}^{-3}$ isopycnal for the initial conditions (solid red line) and modified stratification (dashed red line). The grey line shows the depth of water on the shelf.

transport of oceanic heat towards Kangerdlugssuaq Glacier (KG) between 1993 and 2012.

\section{SETTING}

$\mathrm{KF}$ is more than $60 \mathrm{~km}$ long, between 5 and $\sim 20 \mathrm{~km}$ wide (depending on the defined location of the mouth) and up to 900 m deep (Fig. 1a). It forms the main trunk of a system containing four further tributary fjords. KF connects with Kangerdlugssuaq Trough, which provides a relatively deep (>400 m) pathway between the fjord and the continental shelf break (Christoffersen and others, 2011). KG, which drains into the head of KF, is the largest outlet glacier on Greenland's east coast, responsible for $\sim 5 \%$ of ice discharge from Greenland (Enderlin and others, 2014). Like many of the glaciers along the southeast coast of Greenland, KG has undergone substantial dynamic change since the 1990s, most notably between summer 2004 and spring 2005, when the terminus retreated by $7 \mathrm{~km}$ and accelerated from 7.3 to $13.9 \mathrm{~km} \mathrm{a}^{-1}$ (Howat and others 2007; Luckman and others, 2006). This retreat was broadly coincident with an increase in subsurface ocean temperature off southeast Greenland (Hanna and others, 2009; Rignot and others, 2012), driven by an anomalous inflow of relatively warm, salty subtropical Atlantic water (AW) into the subpolar North Atlantic (Straneo and Heimbach, 2013). Around the coast of Greenland, this AW is overlain by cooler, fresher polar water (PW). Hydrographic observations from KF and Sermilik Fjord (SF, another large fjord in southeast Greenland) show a strong two layer stratification, demonstrating that AW is able to access these deep fjords (Christoffersen and others, 2011; Straneo and others, 2011, 2012; Jackson and others, 2014; Sutherland and others, 2014), though the processes controlling the exchange of waters between the shelf and fjord remain poorly constrained (Straneo and Heimbach, 2013).

Based on the temperature and salinity data used for the initial conditions (Section 3.3; Figs 1b, c), the Rossby deformation radius (e.g. Garvine, 1995) of KF is $\sim 10 \mathrm{~km}$. As such, while significant across-fjord variability is not expected throughout much of the fjord's length, rotational dynamics 
may become significant in the broader zones up-fjord of section $C$ and, more notably, between sections $A$ and $M$ at the fjord mouth (Fig. 1a). A thorough analysis of the estuarine dynamics of KF was undertaken by Sutherland and others (2014), on the basis of hydrographic observations obtained during August 2009. Their results indicated that KF is a highly stratified fjord system in which freshwater forcing (from glacial runoff) and tidal currents are weak and only the strongest along-fjord winds can generate a significant overturning circulation (Sutherland and others, 2014). However, as identified by Sutherland and others (2014), an analysis of conventional estuarine parameter space may not be appropriate for KF. Two features stand out: firstly, intermediary circulation, due to variation in shelf water stratification, may be a key driver of fjord-shelf exchange, and secondly, the input of glacial meltwater runoff at depth (i.e. subglacially) may significantly modify the freshwater forcing effect on the fjord relative to an equivalent input of runoff at the surface. These features are investigated further in this study.

\section{METHODS}

\subsection{Model}

Our model simulations are run using MITgcm (Adcroft and others, 2004), a versatile finite-volume circulation model that has been used in numerous studies of interaction between the ocean and ice masses (e.g. Losch, 2008; Xu and others, 2012; Sciascia and others, 2014). Plumes arising from the subglacial input of meltwater are parameterised using a coupled plume model (Cowton and others, 2015), which uses buoyant plume theory (Morton and others, 1956; Jenkins, 2011) to simulate a plume of halfconical form based on the stratification of the fjord and the prescribed meltwater runoff. This runoff is treated as a mass flux, balanced by a small prescribed barotropic velocity across the open boundary beyond the fjord mouth. The use of this parameterisation makes modelling of the 3-D fjord system computationally possible by removing the need for high resolution, non-hydrostatic simulation of these glacial plumes (e.g. Xu and others, 2013). Submarine melting is calculated from the temperature, salinity and velocity of waters adjacent to the calving front through the commonly used 'three-equation formulation' (Holland and Jenkins, 1999) and, in keeping with existing studies (e.g. Losch, 2008; Xu and others, 2012), is treated as a virtual salt flux.

The model is run using a constant horizontal and vertical grid resolution of $500 \mathrm{~m}$ and $10 \mathrm{~m}$, respectively. Horizontal viscosity, $A_{\mathrm{h}}$ is calculated using a 2-D Smagorinsky scheme with a Smagorinsky coefficient $C_{\mathrm{s}}$ value of 2.2 (Griffies and Hallberg, 2000), while horizontal Laplacian diffusivity $K_{\mathrm{h}}$ is set at $20 \mathrm{~m}^{2} \mathrm{~s}^{-1}$ and vertical Laplacian diffusivity $A_{z}$ and eddy viscosity $K_{z}$ are set at $10^{-5} \mathrm{~m}^{2} \mathrm{~s}^{-1}$. These values were chosen to give a good agreement with observed flow velocities in KF and SF while maintaining numerical stability in the zones of fast-flowing jets that form around the plumes. The sensitivity of the model to these parameters, which may affect the results quantitatively if not qualitatively, is discussed in the Supplementary Material.

\subsection{Model domain}

The model domain incorporates the entirety of $\mathrm{KF}$ and the transition zone where the fjord broadens to merge with the shelf (Fig. 1a). Bathymetry data were sourced primarily from the RSS James Clark Ross cruise JR106b (Dowdeswell, 2004), with additional points digitised from Syvitski and others (1996). The approximate grounding line depth at KG was obtained from the IceBridge MCoRDS L3 gridded ice thickness (version 2) product (Leuschen and Allen, 2013). It is not clear whether the terminus of KG is grounded or floating; the glacier does not however have a significant floating tongue and for simplicity we assume the calving front extends vertically from the grounding line. In the innermost part of the fjord, where the constant presence of ice mélange prohibits surveying, bathymetry was interpolated between the grounding line and the nearest bathymetric data (Fig. 1a). At the smaller glaciers around the periphery of the fjord, where basal topography has not been surveyed, grounding line depths were based on the nearest available bathymetric data (Fig. 1a). The positions of the glacier termini are based on their locations in 2005, and are fixed throughout the experiments.

The modelled area contains two principal sills - the outer sill, where the fjord shallows to join the cross-shelf trough at the southern margin of the domain, and the inner sill, which lies $\sim 13 \mathrm{~km}$ from KG. We define the fjord mouth at a notable constriction $\sim 60 \mathrm{~km}$ from KG ( $\mathrm{M}$ in Fig. 1a) - this simplifies the calculation of transport into and out of the fjord, avoiding the complicating influence of gyres and eddies that can form as the trough broadens to the south of this point.

\subsection{Initial and ocean boundary conditions}

We utilise conductivity-temperature-depth (CTD) data obtained between 3 and 5 September 2004 as part of cruise JR106b (Dowdeswell, 2004) to set the initial conditions, taking the mean of four casts along the fjord centreline (Fig. 1). These data are representative of the broad structure of waters observed adjacent to and within deep East Greenland fjords (e.g. Straneo and others, 2010; Christoffersen and others, 2011; Inall and others, 2014): warmer, saltier AW underlies cooler, fresher PW, while during the summer months surface insolation may generate a layer of warmer, fresher polar surface water (warm) (PSWw) (Figs 1b, c). We define the junction between the PW and AW as occurring at a potential density anomaly $\left(\sigma_{\Theta}\right)$ of $27.3 \mathrm{~kg} \mathrm{~m}^{-3}$, coincident with the transition between the fresher upper layer and saltier deeper waters in the data (Figs 1b, c). It is henceforth referred to as the PW/AW interface, and for the initial conditions is found at a depth $h_{i}=145 \mathrm{~m}$. There are insufficient data to ascertain whether this depth is representative of the mean value of $h_{i}$ in KF in recent years; we do not however expect this to have a significant effect on our results, except in determining the exact depth range of currents that form or change sign at the interface depth.

In all experiments, the initial potential temperature and salinity are set as horizontally uniform. In this way the fjord is initially at rest, with the subsequent circulation a result of the applied forcing. A $5 \mathrm{~km}$ wide relaxation zone is applied at the open boundary on the continental shelf. Within this zone, tracers are relaxed towards the initial conditions over a relaxation timescale that increases linearly from $200 \mathrm{~s}$ at the boundary to $5000 \mathrm{~s}$ at $5 \mathrm{~km}$ from the boundary. For intermediary circulation experiments, periodic variations in potential temperature and salinity are applied in this relaxation zone, as described in the following section. Momentum is also relaxed (towards zero) at this open boundary; this 
relaxation is however only applied in the outermost (i.e. closest to the boundary) $1.5 \mathrm{~km}$ of the relaxation zone, allowing modifications of the temperature and salinity throughout the remaining $3.5 \mathrm{~km}$ of the zone to propagate freely into the fjord.

\subsection{Forcings}

\subsubsection{Intermediary circulation}

Jackson and others (2014) successfully established moorings over winter in KF and, more extensively, in SF, a large fjord with a deep sill located $\sim 350 \mathrm{~km}$ southwest of KF. These moorings showed circulation during the winter months to be dominated by fast (up to $\sim 0.8 \mathrm{~m} \mathrm{~s}^{-1}$ ), periodically-reversing currents, thought to result primarily from coastal storms (Jackson and others, 2014). Ekman transport, due to strong north-easterly (along-shore) winds on the shelf, pushes surface waters towards the coast; this depresses the isopycnals at the fjord mouth, thereby generating density gradients between the shelf and fjord that drive intermediary circulation (Klinck and others, 1981; Straneo and others, 2010) (Fig. 2). Although this mechanism is associated with a small free-surface slope (the free surface on the shelf increases by $\sim 15 \mathrm{~cm}$ during these downwelling-favourable wind events at SF (Jackson and others, 2014), the circulation is almost entirely baroclinic (Klinck and others, 1981). Given the strength of the observed intermediary circulation in SF and KF, it has been suggested that these wind events may allow water properties in large Greenlandic fjords to track shelf variability on timescales of days to weeks (Straneo and others, 2010; Jackson and others, 2014). We aim to test this hypothesis by simulating the response of KF to fluctuations in the depth of isopycnals on the shelf. We emphasise that, in this context, the role of the wind is to modify the shelf stratification, and we do not consider the direct effect of local wind stresses on the fjord surface.

To replicate the effect of the along-shore wind events, we conducted a series of intermediary circulation experiments in which we enforced a periodic depression of the PW/AW interface (Figs $1 \mathrm{~b}, \mathrm{c}$ ) across the $5 \mathrm{~km}$ relaxation zone at the shelf boundary (termed 'shelf forcing'). In this zone, the PW/AW interface was depressed over the course of one day by a depth $\Delta h_{i}$, held there for a period of time $t$, and then restored to its original depth over the course of another day (e.g. solid line in Fig. 3a). In this way, a depression of the interface by $\Delta h_{i}$ for $t$ days means a perturbation of the interface depth at the boundary over a period of $t+2 \mathrm{~d}$. This forcing is similar to the 'top hat' forcing used by Sciascia and others (2014) to simulate intermediary circulation in a 2$\mathrm{D}$ representation of SF. A difficulty encountered by Sciascia and others (2014), who used an idealised two-layer stratification, was that this forcing generated an artificial third-water mass with properties between those of the PW and AW. Because we use realistic temperature and salinity data, with a gradual transition between the properties of the PW and AW layers, we do not experience this issue. The range of values used for $\Delta h_{i}$ and $t$ is based on the observational data from SF (Jackson and others, 2014), with experiments conducted using $\Delta h_{i}=0,20,50$ and $100 \mathrm{~m}$ and $t=1,2$ and $4 \mathrm{~d}$. In some experiments, this forcing is repeated with a periodicity $p$ of 6-14 $d$, as described in Section 5.3.

\subsubsection{Buoyancy-driven circulation}

In a glacial fjord, most fresh water may enter at depth as subglacial runoff, which then rises up the glacier front as a turbulent buoyant plume, entraining fjord waters before reaching neutral buoyancy (or the fjord surface) and flowing downfjord (e.g. Straneo and Cenedese, 2015) (Fig. 2c). To examine the effect of this process on fjord circulation, we input subglacial runoff from 14 glacial catchments situated around the fjord system (Fig. 1a). Runoff $\left(Q_{r}\right)$ was calculated based on simulated $1 \mathrm{~km}$ ice-sheet surface runoff at monthly resolution for the period 1990-2012 (Janssens and Huybrechts, 2000; Hanna and others, 2011), and routed through the individual glacial catchments using the hydraulic potential surface from the ice surface and bed topography (Bamber and others, 2013). Over this period, mean July runoff into the fjord from the 14 catchments is $\sim 900 \mathrm{~m}^{3}$ $\mathrm{s}^{-1}$, with a maximum (in 2005) of $\sim 1600 \mathrm{~m}^{3} \mathrm{~s}^{-1}$. Accordingly, experiments were run using $Q_{r}=0-2000 \mathrm{~m}^{3}$ $\mathrm{s}^{-1}$. This runoff was distributed between the catchments based on the relative magnitude of the mean modelled July runoff from each catchment. All experiments were run a

Intermediary circulation (during winds)

$\Delta h_{i}$

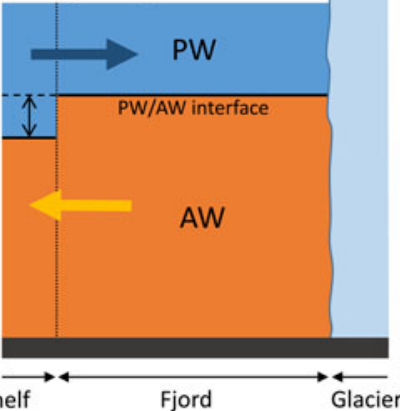

b Intermediary circulation

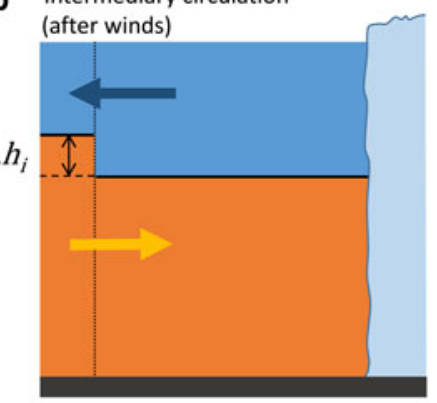

C Buoyancy-driven

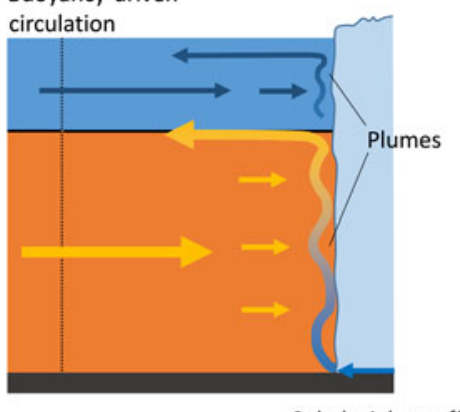

Subglacial runoff

Fig. 2. Schematic depicting the simulated forms of circulation. (a) In the intermediary circulation, the PW/AW interface on the shelf is depressed by a depth $\Delta h_{i}$, causing water to flow into the fjord in the PW layer and out in the AW layer. (b) As the winds cease, the interface then relaxes to its original depth, causing water to flow into the fjord in the AW layer and out of the fjord in the PW layer. (c) The buoyancy-driven circulation is forced primarily by meltwater from the ice-sheet surface, which drains to the bed through crevasses and moulins and so enters the fjord subglacially. This freshwater runoff rises as a buoyant plume adjacent to the glacier front, entraining fjord water. This plume may reach the fjord surface or, if the fjord is stratified, find neutral buoyancy at depth. Water from the plume then flows down-fjord, underlain by a compensatory up-fjord flow replacing the entrained water. In areas not affected by a strong runoff-driven plume, weaker plumes, driven by submarine melting, may form. 

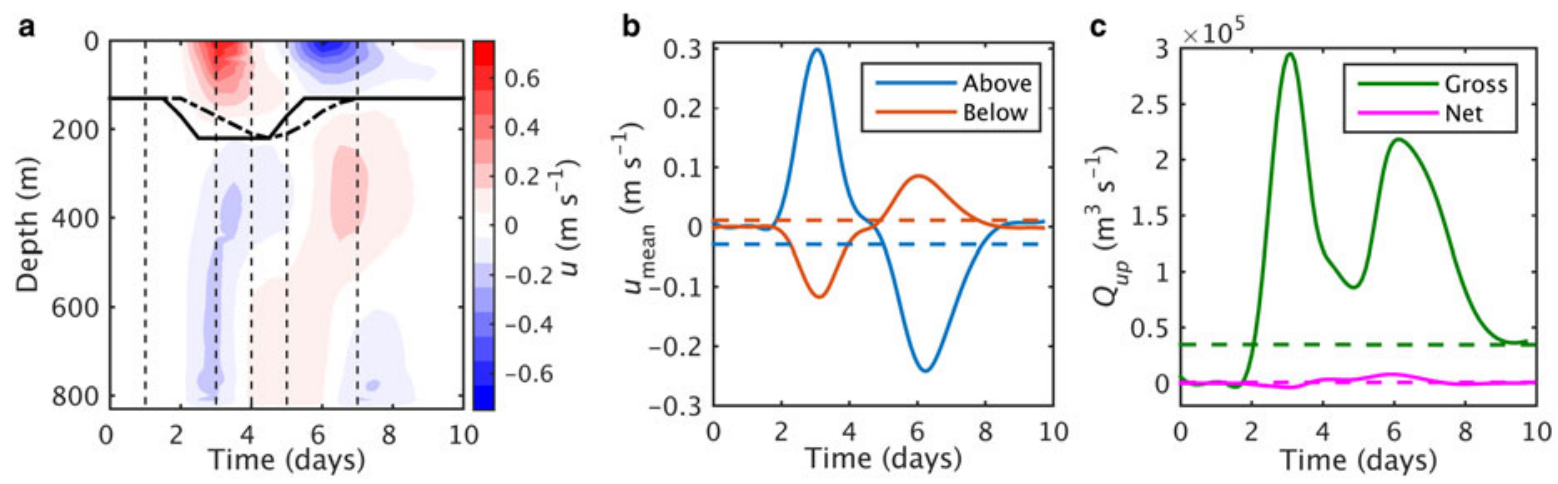

Fig. 3. (a) Hovmöller plot showing along-fjord velocity at the fjord centreline at section B for the standard shelf forcing. Positive velocities (red) denote flow into the fjord. Also shown is the $\sigma_{\Theta}=27.3 \mathrm{~kg} \mathrm{~m}^{-3}$ isopycnal in the relaxation zone $\mathrm{R}$ (solid line) and at section B (thick dashed line). Vertical dashed lines indicate the timing of the snapshots shown in Figure 4a-e. (b) Width and depth averaged up-fjord velocity $\left(u_{\text {mean }}\right)$ across section B for the area of the cross section above (blue) and below (red) the PW/AW interface. (c) Up-fjord volume transport $\left(Q_{u p}\right)$ across section B, displayed in green as gross (i.e. not taking into account the corresponding down-fjord transport) and in magenta as net (i.e. minus the corresponding down-fjord transport) values. In (b-c), solid lines show the standard shelf forcing, while the dashed lines show the summer runoff forcing.

using a constant runoff input until an approximate steady state was reached $(<3 \%$ difference in volume transport across the fjord mouth between two outputs $10 \mathrm{~d}$ apart, normally reached after $\sim 20 \mathrm{~d}$ ).

The strength and distribution of glacial plumes is dependent not only on the total runoff, but also the configuration of the subglacial hydrological system at the grounding line (Slater and others, 2015). Possible configurations exist along a continuum from a single channel to completely distributed (i.e. runoff is distributed evenly along the grounding line). Observational evidence of discrete turbid plumes (e.g. Sole and others, 2011; Chauché and others, 2014) and incised notches (Fried and others, 2015; Rignot and others, 2015) at other glacier termini indicates that much of the meltwater is likely to enter the fjord through one or a few major subglacial channels at each glacier. For the main experiments described in this paper we opt for a scenario in which $90 \%$ of the runoff at each glacier enters through a single channel (at the deepest point on the grounding line), while the remaining $10 \%$ is divided between smaller channels at $500 \mathrm{~m}$ intervals along the grounding line. To assess the effect of this choice, we also run experiments in which runoff at each glacier is evenly distributed between channels at $500 \mathrm{~m}$ intervals, as presented in Section 4.2.

\subsection{Passive tracer}

To track the transport of water from the shelf into the fjord, all water outside of the fjord mouth is assigned a passive-tracer concentration of 1 . This tracer has no influence on fjord dynamics, but allows the propagation of shelf waters into the fjord and mixing of waters within the fjord to be monitored and quantified. For an oscillatory flow like the modelled intermediary circulation, an important consideration is how to treat water that is advected from the fjord out on to the shelf. We opt to immediately assign fjord water a tracer
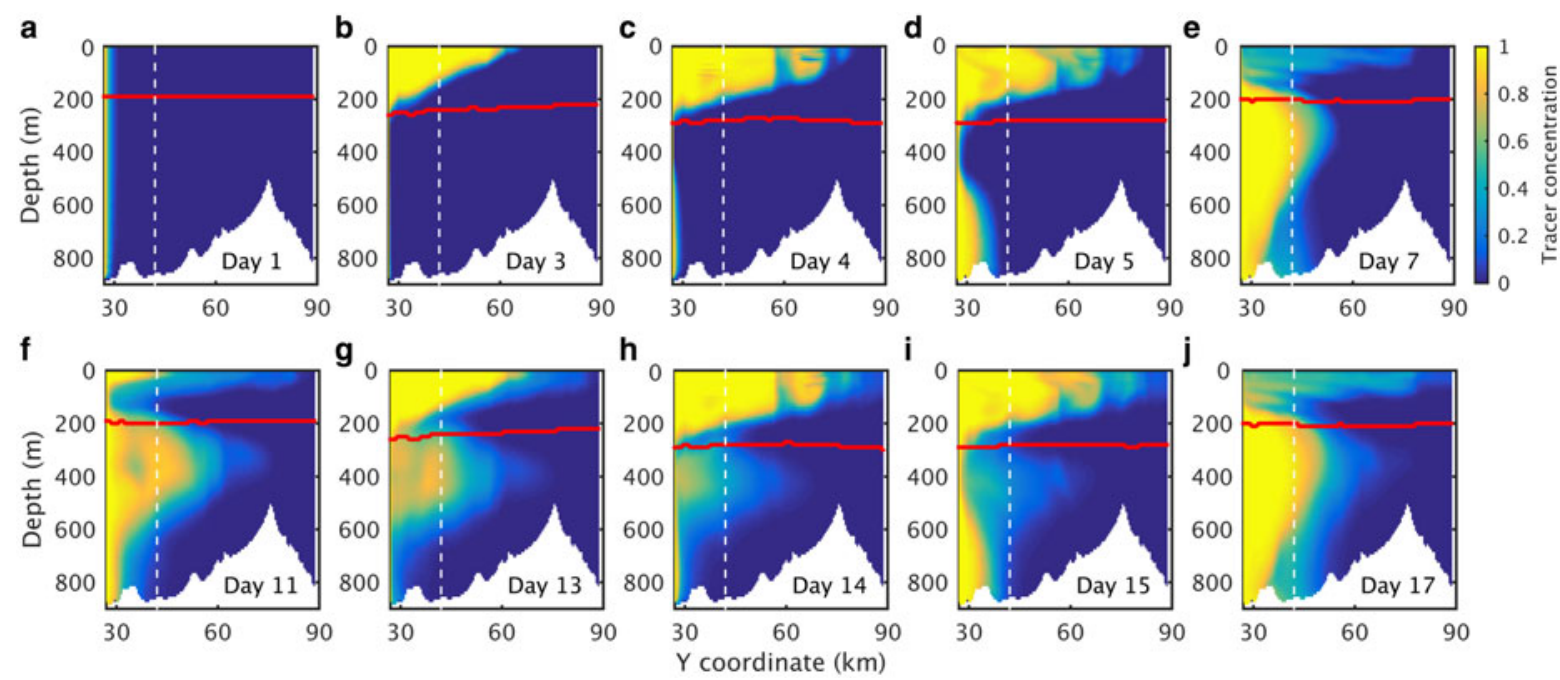

Fig. 4. Fjord centreline sections showing the movement of water from the shelf (represented by a tracer concentration of 1 , yellow) into the fjord over the course of two consecutive wind events using the standard shelf forcing (i.e. with the PW/AW interface on the shelf depressed by $100 \mathrm{~m}$ for two periods of $2 \mathrm{~d}$, centred on days 4 and 14). The $\sigma_{\Theta}=27.3 \mathrm{~kg} \mathrm{~m}^{-3}$ isopycnal is shown by the red line. The velocity profiles across section B (vertical dashed line) for days 1-10 of the simulation are shown in Figure 3a. The scale on the horizontal axis refers to the $Y$ coordinates in Figure 1a, with the fjord mouth section $(M)$ at the left hand limit of the plots. 
value of 1 as it is exported from the fjord, which is equivalent to assuming there is no return flow of exported fjord waters. Return flow to fjords and estuaries has been estimated to lie in the range of $0-50 \%$ (e.g. Luketina, 1998; Gillibrand, 2001), and is highly dependent on the strength of shelf currents and the frequency of the oscillations in the fjord circulation. Any return flow will reduce the efficiency of fjord flushing; because we assume no return flow, our experiments should therefore be considered as upper bounds for the likely rate of fjord renewal for the simulated modes of circulation when considered in isolation.

\section{RESULTS}

\subsection{Intermediary circulation}

We find that current velocities in $\mathrm{KF}$ are commensurate with those observed during large wind events at SF when we force the model with $\Delta h_{i}=100 \mathrm{~m}$, which is at the upper end of the range of isopycnal fluctuations observed at that fjord (Jackson and others, 2014), and $t=2 \mathrm{~d}$ (Figs 3 and 4). This is henceforth referred to as the standard shelf forcing. The resulting exchange can be divided into two phases. In the first, the enforced depression of the PW/AW interface on the shelf is rapidly transmitted up-fjord (Figs $4 \mathrm{a}-\mathrm{C}$ ), facilitated by an inflow of water in the PW layer and outflow of water in the AW layer (Figs 3, 4b, c). In the second phase (after the interface has been held in its depressed position for $2 \mathrm{~d}$ ) the interface on the shelf begins to rise back towards its original depth, causing an outflow of water in the PW layer and an inflow of water from the shelf in the AW layer (Figs 3, 4d, e).

Under this forcing, the maximum velocity in the PW layer at section B peaks at $\sim 0.7 \mathrm{~m} \mathrm{~s}^{-1}$ (Fig. 3a), or $\sim 0.3 \mathrm{~m} \mathrm{~s}^{-1}$ if averaged across the width and depth of the PW layer at this section (Fig. 3b). During the periods of peak flow (Figs $5 a-d)$, circulation within the fjord is predominantly 2-D, though greater across-fjord variability occurs as the trough broadens outside of the fjord mouth (Fig. 5b). The transport of water up- and down-fjord is approximately equal (Fig. 3c) and so the relative velocities in the two layers are determined by their thicknesses: the transport in the PW layer must be accommodated in a thinner layer, and so velocities are greater than those in the AW layer.

During each phase, a volume of water from the shelf is exchanged with an equal volume of water from the fjord. If the fjord is able to fully adjust to the depression of the shelf stratification, the volume exchanged in each phase should be approximately equal to $\Delta h_{i} A$, where $A$ is the plan area of the fjord (e.g. Arneborg, 2004). During the first phase, a volume $V_{l}$ of AW from within the fjord is replaced with $\mathrm{PW}$ from the shelf; in the second phase, a volume $V_{\mathrm{II}}$ of PW from within the fjord is replaced with AW from the shelf. The total volume exchange, $V_{\text {total, }}$ is equal to $V_{I}+V_{I I}$, and can be calculated as the integrated up-fjord volume transport across the fjord mouth over the course of the two phases. $V_{\text {total }}$ should be approximately equal to $2 \Delta h_{i} A$, and there is a good agreement between this idealised scenario and that predicted by the model simulations (Fig. 6a).

$V_{\text {total }}$ may be equal to a significant proportion of the fjord volume: for the standard shelf forcing, $V_{\text {total }}$ is equal to $~ 40 \%$ of the total fjord volume (Fig. 6a). However, because a fraction of the PW imported during the first phase (Figs $4 \mathrm{~b}, \mathrm{c}$ ) is re-exported during the second phase (Figs $4 d$, e), $V_{\text {total }}$ over-estimates the increase in the shelf water content of the fjord over the course of a wind event. Based on the passive tracer concentration, the first instance of the standard shelf forcing results in a new fjord composition that is only $\sim 28 \%$ imported shelf water and $\sim 72 \%$ original fjord water. Similarly, much of the AW imported during the latter phase of the first wind event (Figs 4d, e) is then exported from the fjord during the first phase of the following wind event (Figs 4f, h); for a second wind event $10 \mathrm{~d}$ later, the net
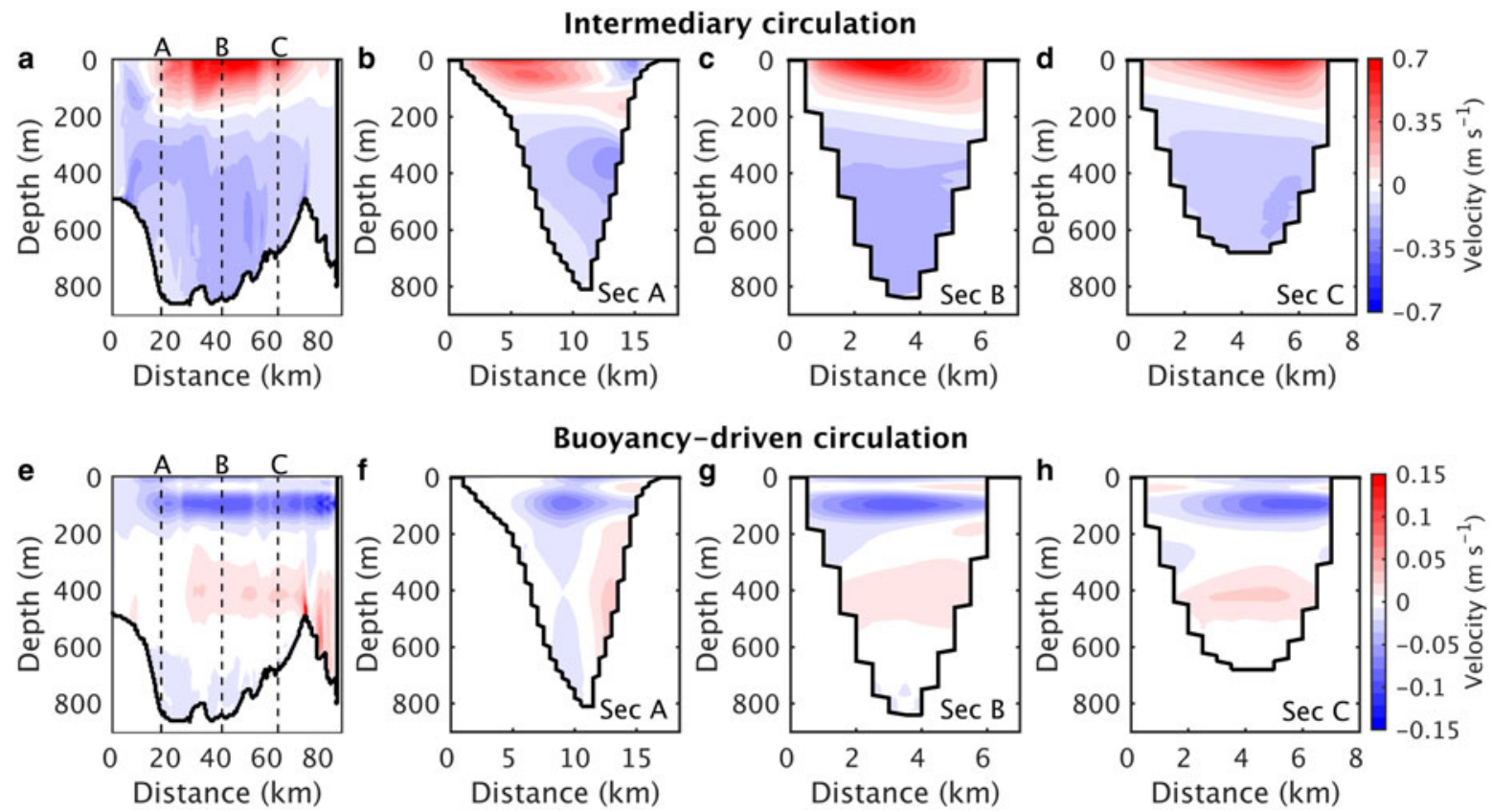

Fig. 5. Snapshots of the along-fjord velocity field, shown along the fjord centreline section (subplots (a) and (e), with KG at the right hand end of the figure) and at across-fjord sections A-C (subplots (b- $d$ ) and ( $f-h)$, shown looking into the fjord). The locations of sections A-C are depicted by dashed lines in (a) and (e). In all cases, positive velocities (red) are directed up-fjord. (a-d) Standard shelf forcing after $3 \mathrm{~d}$, during the peak of the first phase of the circulation (Fig. 3). (e-h) Summer runoff forcing, showing the steady-state circulation. 

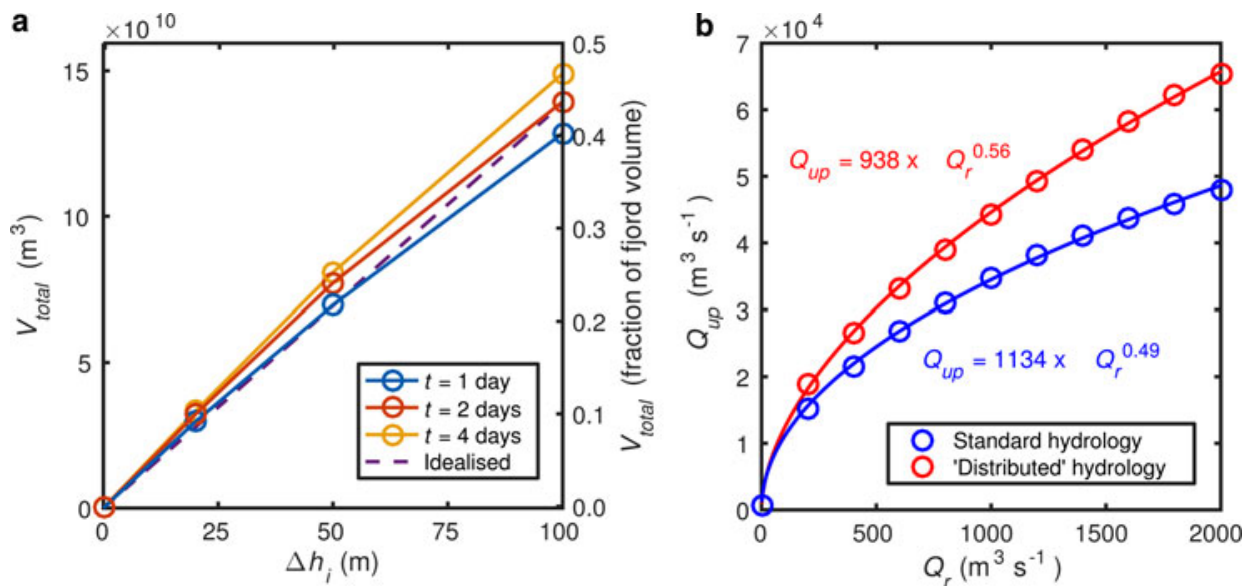

Fig. 6. (a) Volume of water exchanged between the shelf and fjord due to intermediary circulation over a $10 \mathrm{~d}$ window $\left(V_{\text {total }}\right)$, shown as a function of $\Delta h_{i}$ and $t$. Note that $V_{\text {total }}$ is not equal to the volume of new shelf water in the fjord at the end of the $10 \mathrm{~d}$ period, as a proportion of the water imported during the depression of the PW/AW interface is re-exported during the subsequent raising of this interface (Section 4.1). The dashed 'idealised' line shows $V_{\text {total }}$ calculated as $2 \Delta h_{i} A$, where $A$ is the plan area of the fjord. (b) Up-fjord volume transport, $Q_{u p}$, across the fjord mouth as a function of runoff input $Q_{r}$. For the standard hydrology (blue), runoff is input as described in Section 3.4.2. In the 'distributed' hydrology scenario (red), runoff at each glacier is distributed evenly between channels at $500 \mathrm{~m}$ intervals (Section 4.2 ). Both curves are fitted from runoff scenarios at $200 \mathrm{~m}^{3} \mathrm{~s}^{-1}$ intervals (circles).

increase in the shelf water content of the fjord is only $\sim 9 \%$ (Fig. 4j). This recycling of water between the fjord and shelf strongly influences the rate at which the intermediary circulation is able to drive fjord renewal, and is discussed further in Section 5.3.

\subsection{Buoyancy-driven circulation}

An example of the modelled summer buoyancy-driven circulation is shown in Figures $5 \mathrm{e}-\mathrm{h}$, which shows the circulation resulting from the mean July runoff input $\left(900 \mathrm{~m}^{3} \mathrm{~s}^{-1}\right)$ to the fjord (henceforth referred to as the summer runoff forcing). The strongest currents $\left(\sim 0.1 \mathrm{~m} \mathrm{~s}^{-1}\right)$ flow down-fjord immediately above the PW/AW interface ( 50-150 m depth), and result from the intrusion of glacially modified water (GMW, a mixture of runoff, ice melt and fjord water) from many of the larger runoff-driven plumes that reach neutral buoyancy at this steep density gradient. There are also weaker downfjord currents at the surface (resulting from the shallower input of runoff at smaller glaciers) and at $\sim 200-300 \mathrm{~m}$ depth (resulting from the smaller runoff inputs from deep glaciers that lack the buoyancy to reach the PW/AW interface). Below these layers (and to a lesser extent between the surface and interface (e.g. Figs $5 \mathrm{~g}, \mathrm{~h}$ )), flow is directed up-fjord, replacing water entrained into the GMW. There is some across-fjord heterogeneity in the velocity structure, with currents deflected to the right by the Coriolis effect, most notably where the fjord widens as it joins the shelf (Fig. 5f).

We find that the relationship between subglacial meltwater runoff, $Q_{r}$, and the up-fjord volume transport across the fjord mouth, $Q_{u p}$, takes the form $Q_{u p}=a Q_{r}^{b}$, where $a$ is $\sim 1000$ and the exponent $b$ has a value of $\sim 1 / 2$ (Fig. 6b). It has been demonstrated that for a rectangular, flat-bottomed fjord, $Q_{u p}$ is greater for a given $Q_{r}$ if this runoff is divided evenly between a larger number of channels (Carroll and others, 2015). To test whether our chosen distribution of runoff inputs (Section 3.4.2) is an important control on the strength of $Q_{u p}$ in our simulations of $K F$, we experimented with an alternative configuration in which the runoff from each glacier was distributed evenly between channels located at $500 \mathrm{~m}$ intervals along their calving fronts. We find that the volume transport generated by this scenario is up to $\sim 35 \%$ greater (Fig. $6 \mathrm{~b}$ ) than for the standard hydrological configuration (in which $90 \%$ of runoff is input from a single channel at each glacier). The form of the relationship between $Q_{r}$ and $Q_{u p}$ is however similar for the two hydrological configurations, with $Q_{u p}$ proportional to $Q_{r}$ to the power of $\sim 1 / 2$, suggesting the relative variability in the strength of the buoyancy-driven circulation may not be sensitive to the near-terminus hydrology. Nevertheless, it is likely that the distribution of subglacial channels remains a critical control on other features of ice/ocean interaction, particularly the strength and distribution of submarine melting (Fried and others, 2015; Slater and others, 2015), and, as such, improving our knowledge of marine-terminating glacier hydrology remains a key area for research.

\section{DISCUSSION}

\subsection{Comparison of modelled fjord circulation with observations}

Observations from KF and SF have revealed two prominent circulation regimes in these large East Greenland fjords. In the first regime, recorded by continuous over-winter moorings, circulation is dominated by fast (up to $\sim 0.8 \mathrm{~m} \mathrm{~s}^{-1}$ ), periodically reversing currents with a predominantly two-layer structure (Jackson and others, 2014). In the second, captured during a survey in late summer, circulation is characterised by slightly slower currents (up to $\sim 0.4 \mathrm{~m} \mathrm{~s}^{-1}$ ) and a more complex structure, with the strongest down-fjord currents found at $\sim 100-300 \mathrm{~m}$ below the surface (Sutherland and others, 2014).

The two modes of circulation simulated in this paper agree well with these two observed regimes. The simulated intermediary circulation agrees well with the observed winter circulation (Figs 3, 5a-d), demonstrating the influence of shelf conditions on the fjord at a time of year when coastal storms are at their strongest and most frequent, and runoff is at its annual minimum (Jackson and others, 2014). The 
simulated buoyancy-driven circulation more closely resembles the observed summer circulation, particularly with respect to the export of waters in the region of the PW/AW interface (Figs 5e-h). While this similarity alone is insufficient to rule out the possibility that other forcings may influence the observed summer circulation, it is intuitive that buoyancy-driven circulation is of greatest importance at a time of year when runoff of fresh water is highest and storms are less frequent. Further support for this hypothesis comes from Inall and others (2014), who found the temperature and salinity structure of KF during late summer to be commensurate with a steady, layered exchange flow, driven by the input of glacial runoff at depth.

\subsection{Mixing in glacial plumes}

As described in Section 4.2, we find that for the buoyancydriven circulation scenarios, the up-fjord volume transport $Q_{u p}$ is proportional to $Q_{r}^{\sim 1 / 2}$. Q $Q_{u p}$ represents the transport of water required to replace the fjord waters entrained into the GMW and subsequently exported from the fjord. Over the range of $Q_{r}$ used in the experiments $\left(0-2000 \mathrm{~m}^{3} \mathrm{~s}^{-1}\right)$, $Q_{u p}$ is one or two orders of magnitude $>Q_{r}$ (Fig. 6b). Because water is input from multiple glaciers around the fjord, it is difficult to partition this entrainment between that occurring in the runoff-driven plumes (as parameterised using plume theory), and mixing throughout the remainder of the fjord. To examine this more closely, we therefore briefly consider a simpler set up in which only runoff from KG (which in the standard set up accounts for $\sim 55 \%$ of the total runoff input to KF) is included. In this scenario, $87 \%$ of entrainment occurs in the innermost $5 \mathrm{~km}$ of the fjord (up-fjord of section D in Fig. 1a), while 13\% occurs throughout the remainder of the fjord (Table 1). This suggests that the circulation is driven primarily by processes occurring in the plume region adjacent to the glaciers. Care is however required in comparing the rate of entrainment by the vertical plume with that occurring throughout the fjord, as these two processes depend on different model parameterisations: the former is parameterised through buoyant plume theory (Cowton and others, 2015) while the latter is dependent on subgrid mixing schemes in MITgcm. Furthermore, the omission of additional mixing processes including tides and along-fjord winds (e.g. Farmer and Freeland, 1983) may cause mixing in the fjord to be underestimated, in which case $Q_{u p}$ should increase more rapidly between section $D$ and the fjord mouth (Fig. 1a). Nevertheless, a robust finding is that even if mixing throughout the remainder of the fjord is not considered, entrainment into the plumes immediately

Table 1. Net down-fjord volume transport, and up-fjord volume transport $Q_{u p}$ across sections D, C, B and M in Fig. 1a, for a subglacial discharge of $500 \mathrm{~m}^{3} \mathrm{~s}^{-1}$ from KG only. The slight down-fjord decline in net transport occurs because the boundary flux does not perfectly balance the runoff input

\begin{tabular}{lccc}
$\begin{array}{c}\text { Section } \\
\text { Distance from KG } \\
\mathrm{km}\end{array}$ & $\begin{array}{c}\text { Net down-fjord transport } \\
\mathrm{m}^{3} \mathrm{~s}^{-1}\end{array}$ & $\begin{array}{c}Q_{\text {up }} \\
\times 10^{4} \mathrm{~m}^{3} \mathrm{~s}^{-1}\end{array}$ \\
\hline $\mathrm{D}$ & 5 & 499 & 2.7 \\
C & 24 & 499 & 2.7 \\
B & 44 & 498 & 2.8 \\
M & 60 & 497 & 3.1 \\
\hline
\end{tabular}

around the calving front is sufficient to drive a significant exchange between the fjord and shelf during the summer months when there is a substantial runoff input.

\subsection{Renewal of fjord waters}

From a glaciological perspective, the most important function of the fjord circulation is its role in controlling water properties at the calving fronts of marine-terminating glaciers, the largest of which are often found at the heads of fjords. We examine this function by quantifying the rate at which waters within the fjord are renewed by waters from the shelf. This determines the rate at which oceanic heat is supplied to the fjord, and provides an indication of the timescales over which glaciers draining into the fjord may experience the variations in ocean temperature occurring on the shelf beyond the fjord mouth.

The timescale of fjord renewal can be expressed through the turnover time $T_{\mathrm{E}}$ (Prandle, 1984; Gillibrand, 2001), which describes the time taken for fjord/shelf exchange to dilute the original contents of the fjord by a factor $1-\mathrm{e}^{-1}$ (i.e. until the fjord contains $37 \%$ of the original fjord water and $63 \%$ water imported from the shelf). We calculate $T_{\mathrm{E}}$ for the modelled circulation in KF by tracking the movement of the passive tracer into the fjord over time (Figs 7 and 8). In the intermediary circulation scenarios, $T_{\mathrm{E}}$ will depend not only on the magnitude of the applied shelf forcing, but also on the periodicity $p$ at which the perturbation of the interface is applied. Jackson and others (2014) report that in SF the pulses associated with intermediary circulation occur on synoptic timescales, with a dominant periodicity of 4-10 d. Similarly, Harden and others (2011) found the average periodicity of winter storms off East Greenland to vary between $\sim 5$ and $13 \mathrm{~d}$ over the period 1989-2008. Our standard shelf forcing requires a minimum of $6 \mathrm{~d}$ ( $2 \mathrm{~d}$ each with the interface on the shelf in its unperturbed and depressed state, and two transition days; i.e. day 1.5-7.5 in Fig. 3a), and so we test the sensitivity of $T_{\mathrm{E}}$ to $p$ over the range of 6-14 d (Figs 8a, b).

To place these results into context, we compare them with a simple 'slab' model of intermediary circulation (Arneborg, 2004). Based on three decades of observations from Gullmar Fjord, Sweden, Arneborg (2004) proposed that the turnover time of a fjord as a result of intermediary circulation can be approximated as

$$
T_{\mathrm{E}}=p \frac{h_{\mathrm{s}}}{\sigma\left(h_{i}\right)}
$$

where $\sigma\left(h_{i}\right)$ is the standard deviation of the upper layer thickness (in our case synonymous with the standard deviation of the PW/AW interface depth) and $h_{\mathrm{s}}$ is the sill depth (500 m). The solution of the slab model is in reasonable agreement with the fjord simulations, albeit with a greater sensitivity of $T_{\mathrm{E}}$ to $p$ (Fig. 8b). This discrepancy may in part be because we depress $h_{i}$ for a fixed period of $2 \mathrm{~d}$ (Fig. 3a), rather than allowing the duration of the perturbation to scale with $p$, as well as likely reflecting the simplified nature of the slab model. A notable feature of the fjord simulations, in contrast to the slab model, is that there is no further reduction in $T_{\mathrm{E}}$ when $p$ is reduced below $8 \mathrm{~d}$, reflecting the trade-off between the increased frequency of the intermediary circulation events and the reduced exchange that can take place during each event. We are therefore able to place 

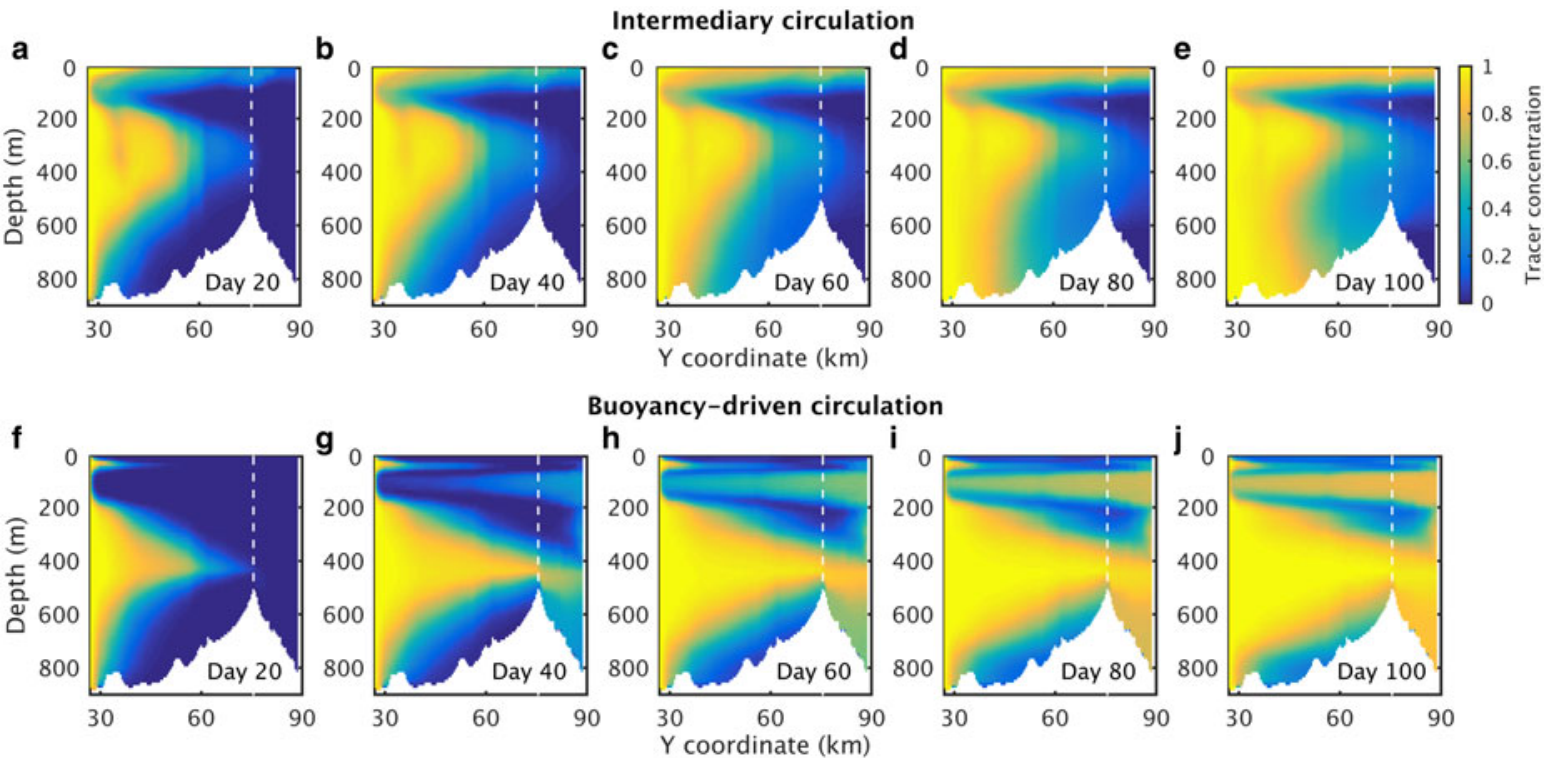

Fig. 7. Fjord centreline sections showing the movement of water from the shelf (represented by a tracer concentration of 1 , yellow) into the fjord over the course of $100 \mathrm{~d}$ for the standard shelf forcing with $p=10 \mathrm{~d}(\mathrm{a}-\mathrm{e})$ and the summer runoff forcing $(\mathrm{f}-\mathrm{j})$ (see also Fig. 8). The scale on the horizontal axis refers to the $Y$-coordinates in Figure $1 \mathrm{a}$. The fjord mouth section $(\mathrm{M})$ forms the left hand limit of the plots, while the upper sill section $(\mathrm{S})$ is marked by the dashed line.

approximate bounds on the value of $T_{\mathrm{E}}$ for the standard shelf forcing - based on a high frequency of winter storms $(p \leq 8 d), T_{\mathrm{E}} \sim 90 \mathrm{~d}$, while for a low frequency of winter storms $(p=13 \mathrm{~d}), T_{\mathrm{E}} \sim 130 \mathrm{~d}$.

A key difference between KF and Gullmar Fjord (and many other smaller, mid-latitude fjords) is the depth of the sill. The ratio $\sigma\left(h_{i}\right) / h_{\mathrm{s}}$ in Eqn (1) represents the relative volume changes associated with the fluctuations in the interface depth. At Gullmar Fjord, Arneborg (2004) reported $\sigma$ $\left(h_{i}\right)=6.6 \mathrm{~m}$ and $h_{\mathrm{s}}=43 \mathrm{~m}$, giving a ratio of 0.15 . For the standard shelf forcing at KF, $\sigma\left(h_{i}\right)=42 \mathrm{~m}$ (for $p=10 \mathrm{~d}$ ) and $h_{\mathrm{s}}=500 \mathrm{~m}$, giving a ratio of 0.084 . This means that for a given value of $p$, the slab model predicts that the turnover time at KF will be nearly a factor of two greater than that for Gullmar Fjord, despite the much larger forcing at KF.
While the intermediary circulation in KF may therefore be capable of generating a vigorous exchange between the fjord and shelf, these findings suggest that the great depth of the fjord reduces the efficacy of this process as a mechanism of fjord renewal. This point is supported by the findings of Gladish and others (2015) who used a 2-D numerical model to examine the circulation of Jakobshavn Isfjord in West Greenland; despite removing the sill to allow free communication between the fjord and shelf, they found that vigorous intermediary circulation was not effective at renewing this $\sim 800 \mathrm{~m}$ deep fjord compared with circulation resulting from submarine ice melt and, more notably, runoff input.

Direct comparison of the two modes of circulation is difficult because the oscillatory nature of the intermediary circulation contrasts with the steady buoyancy-driven circulation. a

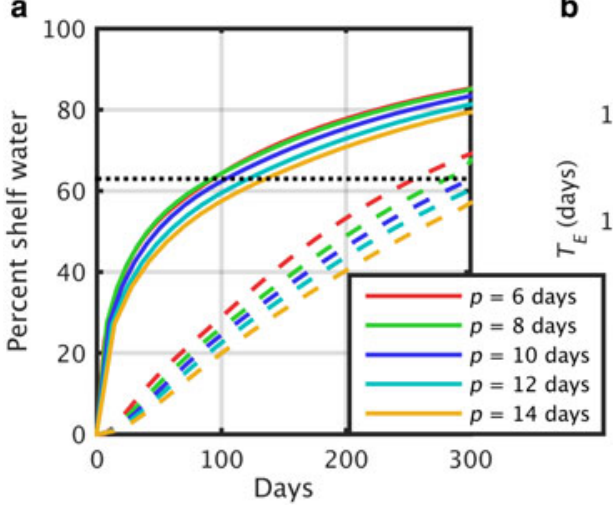

b

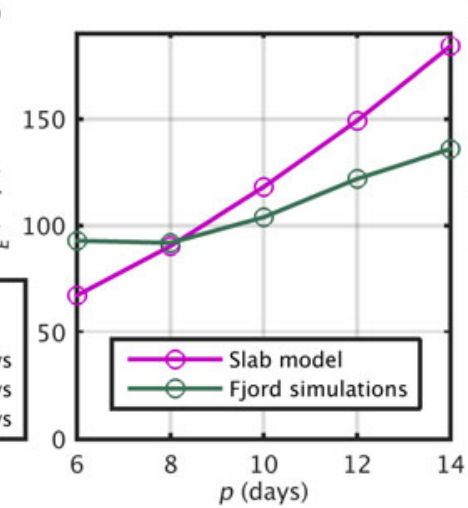

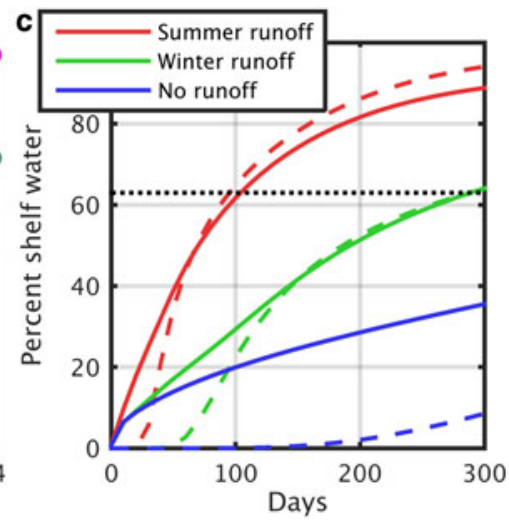

Fig. 8. Renewal rate, based on the propagation of a passive tracer into the fjord (as illustrated in Fig. 7). (a) Intermediary circulation scenarios using the standard shelf forcing $\left(\Delta h_{i}=100 \mathrm{~m}\right.$ and $\left.\mathrm{t}=2 \mathrm{~d}\right)$, and $p=6-14 \mathrm{~d}$. Solid lines show results for the zone up-fjord of the fjord mouth $\mathrm{M}$, while dashed lines show results for only the zone up-fjord of the inner sill S. Water below $500 \mathrm{~m}$ (the depth of the outer and inner sill) is not considered for consistency with Eqn (1). The dotted line shows the level at which the original fjord water has been diluted by a factor of $1-\mathrm{e}^{-1}$ (i.e. to $37 \%$ ) by shelf water - the turnover time for the scenarios is defined as the time when the curves intersect this line (Section 5.3.). (b) Turnover times for the standard shelf forcing using $p=6-14 \mathrm{~d}$, based on the slab model of Arneborg (2004) (purple) and the numerical fjord simulations shown in (a) (green). (c) As for (a), but for the buoyancy-driven circulation scenarios, showing the summer runoff forcing $\left(Q_{r}=900 \mathrm{~m}^{3} \mathrm{~s}^{-1}\right)$, winter runoff forcing $\left(Q_{r}=90 \mathrm{~m}^{3} \mathrm{~s}^{-1}\right)$ and no runoff forcing $\left(Q_{r}=0 \mathrm{~m}^{3} \mathrm{~s}^{-1}\right)$. 
The total volume exchange, $V_{\text {total, }}$ associated with each instance of the standard shelf forcing is $\sim 1.4 \times 10^{11} \mathrm{~m}^{3}$ (Fig. 6a). Over an equivalent $10 \mathrm{~d}$ period, the cumulative up-fjord transport of water (i.e. time-integrated $Q_{u p}$ ) due to the summer runoff forcing is only $\sim 0.3 \times 10^{11} \mathrm{~m}^{3}$. The turnover times (calculated using the passive tracer) for the intermediary circulation and summer buoyancy-driven circulation scenarios are however much more similar, being $105 \mathrm{~d}$ for the summer buoyancy-driven circulation and 90-130 d (for $p=6-13 \mathrm{~d}$ ) for the intermediary circulation (Fig. 8). Furthermore, and critically for ocean/ice interaction, the modelled summer buoyancy-driven circulation is much more effective at transporting water to the fjord head relative to the intermediary circulation. In the summer runoff forcing scenario, water from outside the fjord mouth reaches the fjord head within $40 \mathrm{~d}$ (Fig. 7g). After $100 \mathrm{~d}$, this buoyancydriven circulation has replaced $\sim 65 \%$ of the waters within the innermost $13 \mathrm{~km}$ of the fjord (i.e. the branch containing KG) with shelf water, compared with $<30 \%$ for the intermediary circulation scenarios (Figs 7,8 ).

These differences in the efficiency of fjord renewal between the intermediary and buoyancy-driven circulation occur for two main reasons. Firstly, the buoyancy-driven circulation is steady over time during the melt season, with a persistent up-fjord current at depth (Figs 3b, c, 5e-h, 7f-j). This contrasts with the intermediary circulation, where the same water may be exchanged repeatedly across the fjord mouth as the currents reverse (Figs 3,4). Secondly, the buoyancy-driven circulation is driven by the inputs of freshwater at the head of the fjords, meaning the circulation is effective at drawing water all the way to the glacier termini. The intermediary circulation, on the other hand, is most effective at exchanging water in the outer part of the fjord, and much less effective at driving shelf water up to the fjord heads. It is also important to note that for the summer runoff forcing, the proportion of shelf water in the inner fjord becomes greater than the average throughout the fjord after $\sim 70 \mathrm{~d}$ (Fig. 8a). This occurs because the plumes near to the KG terminus generate significant vertical mixing, redistributing shelf waters through a greater part of the water column (Fig. 7h)

The summer runoff forcing is based on the input to the fjord of $\sim 900 \mathrm{~m}^{3} \mathrm{~s}^{-1}$ of runoff from surface melting of the ice sheet, but this will be negligible during the $\sim 7$ non-summer months. It is however likely that some year-round input of runoff continues due to basal melting of the ice sheet through geothermal and frictional heating (Christoffersen and others, 2012). This flux is hard to quantify, but a likely indication of the approximate magnitude comes from Store Glacier, a large marine-terminating outlet glacier in West Greenland, where Chauché (2016) used hydrographic data from the fjord to estimate an average winter runoff of $36 \pm 22 \mathrm{~m}^{3} \mathrm{~s}^{-1}$. Taking $50 \mathrm{~m}^{3} \mathrm{~s}^{-1}$ as a generous estimate for winter runoff from $K G$ and scaling runoff input from the other glaciers accordingly (see Section 3.4.2) gives a total winter runoff forcing of $\sim 90 \mathrm{~m}^{3} \mathrm{~s}^{-1}$, an order of magnitude smaller than the summer runoff forcing. In this scenario, $T_{\mathrm{E}}(300 \mathrm{~d})$ far exceeds that for the summer buoyancy-driven circulation and the intermediary circulation scenarios ( 100 d) (Fig. 8). In the inner fjord, however, there is a similar rate of increase in the shelf water concentration between the winter runoff scenario and the intermediary circulation scenarios, with this concentration reaching $\sim 60 \%$ after $300 \mathrm{~d}$ (Fig. 8). Alternatively, a conservative estimate of the winter buoyancy-driven circulation can be obtained by specifying zero runoff such that circulation is driven only by submarine melting (although these results should be treated cautiously as melt-driven convection at the calving fronts will be poorly represented at the coarse model resolution and melting of icebergs and ice mélange is not considered). In this no runoff forcing scenario, the buoyancy-driven circulation is much weaker such that only $\sim 35 \%$ of the fjord volume (and $<10 \%$ of the upper fjord) is replaced with shelf waters over the $300 \mathrm{~d}$ of the model run (Fig. 8c). These experiments indicate that while we expect buoyancy-driven circulation to dominate the transport of shelf waters to the inner fjord during the summer months, outside of the melt season the dominant mode of transport is less clear. If there is a sufficient input of runoff from basal melting, then buoyancy-driven circulation may remain significant year-round; if not, then intermediary circulation will likely dominate in winter. In either case, the weak currents associated with the winter buoyancy-driven circulation will likely be obscured by the intermediary circulation, consistent with the finding by Jackson and others (2014) that buoyancy-driven circulation is not visible in winter velocity observations obtained at SF.

It should also be noted that while we find the simulated intermediary circulation is comparatively limited in its ability to advect new shelf waters to the fjord head, we do not exclude the possibility that alternative shelf-driven exchanges could be more effective at renewing waters along the length of the fjord. In our simulations, we have focused on the intermediary circulation driven by alongshore shelf winds, given the proposed importance of this mechanism for fjord renewal (e.g. Straneo and Cenedese, 2015). However, it is possible, for example, that the arrival of a new water mass on the shelf, or the steering of ocean currents along the cross-shelf troughs leading to KF and SF (e.g. Christoffersen and others, 2011; Magaldi and others, 2011), could drive an exchange that is more effective at advecting shelf water to the fjord head. Assessment of these mechanisms would require observations from and/or modelling of a much larger region of the shelf surrounding the fjord, and as such lies beyond the scope of this paper.

\subsection{Up-fjord heat transport due to buoyancy-driven circulation}

It has been hypothesised that the retreat of many of Greenland's marine-terminating glaciers has been driven by the warming of ocean waters off Greenland since the mid-1990s (Straneo and Heimbach, 2013). Our results indicate that buoyancy-driven circulation, resulting from the input of glacial runoff, provides an effective mechanism for the transport of this oceanic heat from the shelf to the glaciers at sub-seasonal timescales. Through this mechanism the heat transport will increase not only with ocean temperature but also with atmospheric temperature, which controls the input of meltwater runoff to the fjord. To examine the response of heat transport to climatic variability, we calculated the heat transport $H$ due to the buoyancy-driven mode of circulation into KF at monthly intervals over a 19 year period from 1993 to 2011. This is calculated as

$$
H=c_{p} \rho_{0} Q_{u p}\left(\theta_{\text {shelf }}-\theta_{f}\right)
$$

where $c_{\mathrm{p}}$ is the specific heat capacity of sea water (3980 J $\left.\mathrm{kg}^{-1} \mathrm{~K}^{-1}\right), \rho_{0}$ is a reference density $\left(1027 \mathrm{~kg} \mathrm{~m}^{-3}\right)$ and $\theta_{\text {shelf }}$ is the potential temperature of shelf water at the fjord 
mouth $\left({ }^{\circ} \mathrm{C}\right) . \theta_{f}$ is the depth-averaged freezing point $\left(-2.17^{\circ} \mathrm{C}\right.$, based on the initial salinity stratification; Fig. 1c); we use this value as the reference temperature because our primary interest lies in the variability in the heat available for melting at the calving front.

To obtain a time series of $\theta_{\text {shelf, }}$ we utilise the GLORYS2V3 $1 / 4^{\circ}$ ocean reanalysis product (Ferry and others, 2012). $\theta_{\text {shelf }}$ is taken as the depth-averaged temperature of these reanalysis data between 200 and 500 m depth (Fig. 9a), shown in the modelling experiments to represent the main depth-range of up-fjord flow (Figs $7 f-j$ ), in the cell where KF joins the shelf (the fjord itself is not resolved in the reanalysis). Comparison with available hydrographic surveys at the fjord mouth (e.g. Inall and others, 2014; Sutherland and others, 2014) suggests the reanalysis AW temperature is typically $\sim 1^{\circ} \mathrm{C}$ warmer than the observations, which may reflect across-shelf cooling of subsurface waters not captured by the reanalysis (e.g. Christoffersen and others, 2011). This bias will act to slightly reduce the apparent relative variability in $\theta_{\text {shelf }}-\theta_{f}$, meaning the calculated relative change in $H$ may be slightly underestimated. For example, an increase in $\theta_{\text {shelf }}$ from 2 to $3{ }^{\circ} \mathrm{C}$ would cause $H$ to increase by $\sim 25 \%$, whereas an increase in $\theta_{\text {shelf }}$ from 3 to $4{ }^{\circ} \mathrm{C}$ would cause $H$ to increase by only $\sim 20 \%$.

$Q_{u p}$ is calculated according to the values given for the 'standard hydrology' curve in Figure 6b, using the modelled catchment-wide runoff input to KF over this period (Fig. 9a). Given the uncertainty with respect to the basal melt rate, and how this may vary over time (e.g. due to glacier acceleration), we do not prescribe a contribution to runoff from basal melting. The results of this section therefore reflect only the buoyancy-driven circulation in response to the runoff of meltwater from melting of the ice-sheet surface.

We emphasise that we seek here to estimate only the up-fjord transport of oceanic heat due to buoyancy-driven circulation, and not the difference between the up- and down-fjord heat transport, which would require accurate quantification of the use of this heat in melting of the glacier calving fronts or icebergs/ice mélange. In this approach we differ from previous numerical modelling studies that have sought to quantify the submarine melt rate resulting from variation in runoff and fjord water temperature (e.g. Sciascia and others, 2013; Xu and others, 2013; Slater and others, 2015). We do this for two reasons. Firstly, modelled submarine melt rates are strongly dependent on turbulent transfer coefficients within the model (Holland and Jenkins, 1999) and the prescribed distribution of runoff at the grounding line (Slater and others, 2015), both of which are poorly constrained by observations. Secondly, it remains unclear whether (and if so how) submarine melting influences the stability of fast flowing outlet glaciers such as $K G$, where the thickness and rigidity of ice mélange and the seasonal duration of land-fast sea ice may also be important controls on calving rate (e.g. Amundson and others, 2010; Christoffersen and others, 2012; Nick and others, 2013). By focusing simply on the heat available in the proximity of $\mathrm{KG}^{\prime}$ 's terminus, we avoid prescribing a specific mechanism linking ocean temperature to glacier stability, instead recognising that an increase in oceanic heat availability may lead to glacier retreat through one or a combination of mechanisms.

The modelled up-fjord heat transport due to buoyancydriven circulation is shown in Figure 9b. The sub-linearity of the relationship between runoff and volume transport reduces the interannual variability in heat transport relative to runoff. Nevertheless, both runoff and ocean temperature increased markedly in the early 2000s, resulting in a $50 \%$ increase in the mean value of $H$ between the periods 1993-2001 and 2002-11 (Fig. 9). The timing of this increase agrees closely with the acceleration of mass loss from KG, with the glacier thinning between 2003 and 2004 then undergoing a phase of rapid retreat and thinning through 2004/05 (Luckman and others, 2006; Howat and others, 2007), suggesting the possible role of oceanic heat in triggering retreat. While our modelling work has focused on KF and $\mathrm{KG}$, this finding is likely to be equally applicable to many
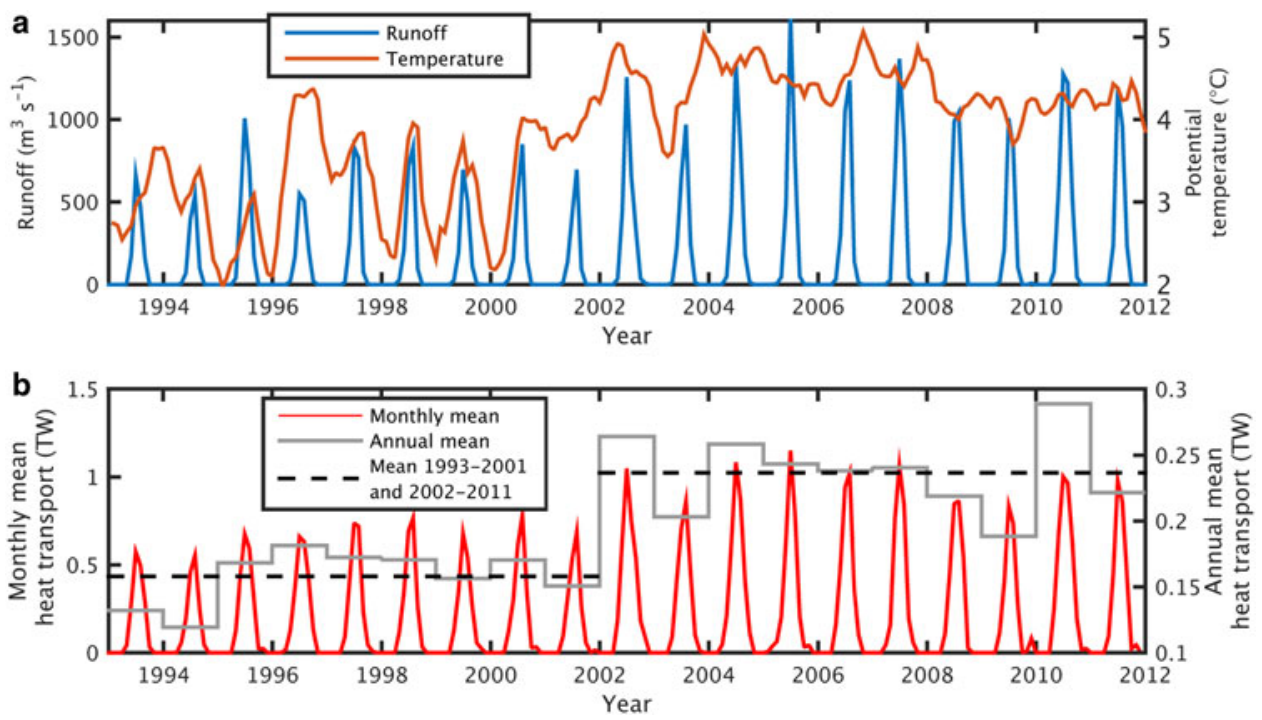

Fig. 9. (a) Modelled catchment-wide runoff into KF due to surface melting (Section 3.4.2), and mean potential temperature at the fjord mouth between 200 and $500 \mathrm{~m}$ depth from GLORYS2V3 1/4 ocean reanalysis data (Ferry and others, 2012). (b) Modelled up-fjord heat transport across the fjord mouth due to buoyancy-driven circulation, as forced using the runoff time series shown in (a). Heat transport is averaged over monthly (red) and annual (grey) time intervals and over the periods 1993-2001 and 2002-2011 (black dashes). Note the different scales on the vertical axes for monthly and annual mean heat transport. 
glaciers along Greenland's southeast coast, which underwent a synchronous thinning and retreat in response to regional oceanic and atmospheric warming at this time (e.g. Seale and others, 2011).

\section{CONCLUSIONS}

In this paper we have used a 3-D numerical model of KF, East Greenland, to examine controls on fjord/shelf exchange and the transport of oceanic heat to marine-terminating glaciers. We have focussed on two key mechanisms: intermediary circulation forced by fluctuations in the depth of isopycnals on the shelf (due to the passage of coastal storms), and buoyancy-driven circulation forced by the input of glacial meltwater.

Comparison between the modelled circulation and field observations (Jackson and others, 2014; Sutherland and others, 2014) demonstrates that the model captures these key mechanisms of circulation in the fjord. The intermediary circulation takes the form of a fast (up to $\sim 0.7 \mathrm{~m} \mathrm{~s}^{-1}$ ), periodically reversing, two-layer exchange. The buoyancy-driven circulation (forced by the input of runoff at depth from multiple glaciers) forms a more complex multi-celled circulation, with the strongest outflow $\left(\sim 0.1 \mathrm{~m} \mathrm{~s}^{-1}\right)$ occurring around the PW/AW interface. We find that the rate of buoyancy-driven exchange between the fjord and shelf (controlled principally by mixing in plumes at the glacier termini) scales with runoff to the power of $\sim 1 / 2$, with the exchange rate one to two orders of magnitude greater than the initial runoff input.

Over short timescales, and in keeping with observations, we find that exchanges associated with intermediary circulation can exceed those due to buoyancy-driven circulation. During a $10 \mathrm{~d}$ period associated with the passage of a coastal storm, the modelled intermediary circulation can exchange up to $\sim 25 \%$ of the fjord volume with shelf waters. In comparison, at its strongest in midsummer, the buoyancydriven circulation replaces $\sim 10 \%$ of the fjord volume with shelf waters over an equivalent $10 \mathrm{~d}$ period. The rapid exchange associated with the intermediary circulation means that water properties in the outer reaches of the fjord are able to track changes occurring on the shelf over timescales of only a few days.

In spite of this rapid exchange in the outer fjord, we find that intermediary circulation is not effective at transporting waters from the shelf to the glacier termini. This is because intermediary circulation is periodically reversing, meaning imported shelf waters tend to be subsequently re-exported back to the shelf rather than transported further up-fjord. In contrast, the temporal consistency of buoyancy-driven circulation means that it is much more effective at transporting subsurface waters from the shelf to the glaciers at the fjord head. This is illustrated by calculating the turnover time for the innermost $13 \mathrm{~km}$ of the fjord: $\sim 100 \mathrm{~d}$ for the buoyancydriven circulation (under summer conditions), compared with $>250 \mathrm{~d}$ for the most intense intermediary circulation scenarios.

During the summer months, when meltwater runoff is greatest and coastal storms are weaker and less frequent, we therefore expect buoyancy-driven circulation to dominate the up-fjord transport of oceanic heat. Outside of the melt season, runoff from ice-sheet basal melting may be sufficient to allow buoyancy-driven circulation to continue to play a significant, albeit reduced, role; if not, intermediary circulation will be the dominant mode of fjord circulation during the winter months.

Because the strength of the buoyancy-driven circulation increases with runoff, a greater quantity of oceanic heat will be advected to the glaciers during longer and warmer summers. We estimate that mean heat transport to KG due to buoyancy-driven circulation increased $\sim 50 \%$ between the periods 1993-2001 and 2002-11, with annual up-fjord heat transport in 2004/05 double that of the cooler years of the early to mid-1990s. This increased heat availability has the potential to influence glacier stability by increasing submarine melting at the calving front, weakening the ice mélange or decreasing the duration of seasonal sea-ice cover, all of which may have contributed to the retreat of KG (and many other marine-terminating glaciers in southeast Greenland) in the early years of the 21 st century.

\section{SUPPLEMENTARY MATERIAL}

The supplementary material for this article can be found at http://dx.doi.org/10.1017/jog.2016.117

\section{ACKNOWLEDGEMENTS}

The authors would like to thank: Julian Dowdeswell and Karen Heywood for the provision of bathymetry and temperature and salinity data respectively (collected during James Clark Ross Cruise JR106b with the support of NERC's Autosub Under Ice Thematic Programme and NERC grant NER/T/S/2000/0099); the GLORYS project for providing ocean reanalysis data (GLORYS is jointly conducted by MERCATOR OCEAN, CORIOLIS and CNRS/INSU); CReSIS for the provision of basal topography for KG (generated with support from NSF grant ANT-0424589 and NASA grant NNX10AT68G); Philippe Huybrechts for his contribution to the runoff model used in this paper; and two anonymous referees whose constructive and insightful reviews made a valuable contribution to the paper. This work was funded by NERC grant NE/K014609/1 to Peter Nienow and Andrew Sole and a NERC studentship to Donald Slater. Edward Hanna and David Wilton acknowledge support from NERC grant NE/H023402/1. Please contact the corresponding author at tom.cowton@st-andrews.ac.uk to obtain the data or numerical model described in this paper.

\section{REFERENCES}

Adcroft A, Hill C, Campin J, Marshall J and Heimbach P (2004) Overview of the formulation and numerics of the MIT GCM. In Proceedings of the ECMWF Seminar Series on Numerical Methods, Recent Developments in Numerical Methods for Atmosphere and Ocean Modelling, 139-149.

Amundson $\mathrm{J}$ and 5 others (2010) Ice melange dynamics and implications for terminus stability, Jakobshavn Isbrae Greenland. J. Geophys. Res.-Earth Surf., 115, F01005 (doi: 10.1029/ 2009jf001405)

Arneborg L (2004) Turnover times for the water above sill level in Gullmar Fjord. Cont. Shelf Res., 24(4-5), 443-460 (doi: 10.1016/j.csr.2003.12.005)

Bamber J and 10 others (2013) A new bed elevation dataset for Greenland. Cryosphere, 7(2), 499-510 (doi: 10.5194/tc-7-499-2013)

Carroll D and 5 others (2015) Modeling turbulent subglacial meltwater plumes: implications for fjord-scale buoyancy-driven circulation. J. Phys. Oceanogr, 45, 2169-2185 (doi: 10.1175/ JPO-D-15-0033.1) 
Chauché N (2016) Glacier-Ocean interaction at Store Glacier (West Greenland). Doctor of Philosophy, Department of Geography and Earth Science, Aberystwyth University.

Chauché $\mathrm{N}$ and 8 others (2014) Ice-ocean interaction and calving front morphology at two west Greenland tidewater outlet glaciers. Cryosphere, 8(4), 1457-1468 (doi: 10.5194/tc-8-1457-2014)

Christoffersen P and 7 others (2011) Warming of waters in an East Greenland fjord prior to glacier retreat: mechanisms and connection to large-scale atmospheric conditions. Cryosphere, 5, 701714 (doi: 10.5194/tc-5-701-2011)

Christoffersen P, O'Leary M, Van Angelen J and van den Broeke M (2012) Partitioning effects from ocean and atmosphere on the calving stability of Kangerdlugssuaq Glacier, East Greenland. Ann. Glaciol. 53(60), 249-256 (doi: 10.3189/2012AoG60A087)

Cowton T, Slater D, Sole A, Goldberg D and Nienow P (2015) Modeling the impact of glacial runoff on fjord circulation and submarine melt rate using a new subgrid-scale parameterization for glacial plumes. J. Geophys. Res., 120, 796-812 (doi: 10.1002/2014JC010324)

Dowdeswell J (2004) Cruise report - JR106b. RSS James Clark Ross. NERC Autosub Under Ice thematic programme, Kangerdlugssuaq Fjord and shelf, east Greenland.

Enderlin E and 5 others (2014) An improved mass budget for the Greenland ice sheet. Geophys. Res. Lett., 41(3), 866-872 (doi: 10.1002/2013gl059010)

Farmer D and Freeland H (1983) The physical oceanography of fjords. Prog. Oceanogr., 12(2), 147-219 (doi: 10.1016/00796611(83)90004-6)

Ferry N and 6 others (2012) Scientific Validation Report (ScVR) for Reprocessed Analysis and Reanalysis. MyOcean project report, MYO-WP04-ScCV-rea-MERCATOR-V1.0.

Fried $\mathrm{M}$ and 8 others (2015) Distributed subglacial discharge drives significant submarine melt at a Greenland tidewater glacier. Geophys. Res. Lett., 42(21), 1944-8007 (doi: 10.1002/ 2015GL065806)

Garvine R (1995) A dynamical system for classifying buoyant coastal discharges. Cont. Shelf Res., 15(13), 1585-1596 (doi: 10.1016/ 0278-4343(94)00065-u)

Gillibrand P (2001) Calculating exchange times in a Scottish fjord using a two-dimensional, laterally-integrated numerical model. Estuar. Coast. Shelf Sci. 53(4), 437-449 (doi: 10.1006/ ecss.1999.0624)

Gladish C, Holland D, Rosing-Asvid A, Behrens J and Boje J (2015) Oceanic boundary conditions for Jakobshavn glacier. Part I: variability and renewal of ilulissat icefjord waters, 2001-14. J. Phys. Oceanogr., 45(1), 3-32 (doi: 10.1175/jpo-d-14-0044.1)

Griffies S and Hallberg R (2000) Biharmonic friction with a Smagorinsky-like viscosity for use in large-scale eddy-permitting ocean models. Mon. Weather Rev., 128(8), 2935-2946 (doi: 10.1175/1520-0493(2000)128<2935:bfwasl > 2.0.co;2)

Hanna E and 5 others (2009) Hydrologic response of the Greenland ice sheet: the role of oceanographic warming. Hydrol. Process., 23(1), 7-30 (doi: 10.1002/hyp.7090)

Hanna E and 12 others (2011) Greenland Ice Sheet surface mass balance 1870 to 2010 based on Twentieth Century Reanalysis, and links with global climate forcing. J. Geophys. Res.: Atmos. (1984-2012), 116(D24), D24121 (doi: 10.1029/2011JD016387)

Harden B, Renfrew I and Petersen G (2011) A climatology of wintertime barrier winds off Southeast Greenland. J. Clim., 24(17), 4701-4717 (doi: 10.1175/2011jcli4113.1)

Holland D and Jenkins A (1999) Modeling thermodynamic iceocean interactions at the base of an ice shelf. J. Phys. Oceanogr., 29(8), 1787-1800 (doi: 10.1175/1520-0485(1999) $029<1787$ :mtioia $>2.0$. co;2)

Howat I, Joughin I and Scambos T (2007) Rapid changes in ice discharge from Greenland outlet glaciers. Science, 315(5818), 1559-1561 (doi: 10.1126/science.1138478)

Inall $M$ and 6 others (2014) Oceanic heat delivery via Kangerdlugssuaq Fjord to the south-east Greenland ice sheet. J.
Geophys. Res.: Oceans, 119(2), 631-645 (doi: 10.1002/ 2013JC009295)

Jackson R, Straneo F and Sutherland D (2014) Externally forced fluctuations in ocean temperature at Greenland glaciers in nonsummer months. Nat. Geosci., 7(7), 503-508 (doi: 10.1038/ ngeo2186)

Janssens I and Huybrechts P (2000) The treatment of meltwater retention in mass-balance parameterizations of the Greenland ice sheet. Ann. Glaciol. 31, 133-140 (doi: 10.3189/ 172756400781819941)

Jenkins A (2011) Convection-driven melting near the grounding lines of ice shelves and tidewater glaciers. J. Phys. Oceanogr., 41(12), 2279-2294 (doi: 10.1175/jpo-d-11-03.1)

Klinck J, Obrien J and Svendsen H (1981) A simple model of fjord and coastal circulation interaction. J. Phys. Oceanogr., 11(12), 1612-1626 (doi: 10.1175/1520-0485(1981)011<1612:asmofa> 2.0.co;2)

Leuschen C and Allen C (2013) IceBridge MCoRDS L3 Gridded Ice Thickness, Surface and Bottom, Version 2, Kangerdlugssuaq 2008-2012 Composite. NASA DAAC at the National Snow and Ice Data Center, Boulder, Colorado, USA.

Losch M (2008) Modeling ice shelf cavities in a z coordinate ocean general circulation model. J. Geophys. Res.-Oceans, 113(C8), C08043 (doi: 10.1029/2007jc004368)

Luckman A, Murray T, de Lange R and Hanna E (2006) Rapid and synchronous ice-dynamic changes in East Greenland. Geophys. Res. Lett., 33(3), L03503 (doi: 10.1059/2005gl025048)

Luketina D (1998) Simple tidal prism models revisited. Estuar. Coast. Shelf Sci., 46(1), 77-84 (doi: 10.1006/ecss.1997.0235)

Magaldi M, Haine T and Pickart R (2011) On the nature and variability of the East Greenland spill jet: a case study in summer 2003. J. Phys. Oceanogr., 41(12), 2307-2327 (doi: 10.1175/jpo-d-1005004.1)

Morton B, Taylor G and Taylor J (1956) Turbulent gravitational convection from maintained and instantaneous sources. Proc. R. Soc. London Ser. A-Math. Phys. Sci., 234(1196), 1-23 (doi: WOS:A1956WU30300001)

Nick F and 7 others (2013) Future sea-level rise from Greenland's main outlet glaciers in a warming climate. Nature, 497(7448), 235-238 (doi: 10.1038/nature12068)

Prandle D (1984) A modelling study of the mixing of Cs-137 in the seas of the European continental shelf. Philos. Trans. R. Soc. AMath. Phys. Eng. Sci., 310(1513), 407-436 (doi: 10.1098/ rsta.1984.0002)

Rignot $\mathrm{E}$ and Kanagaratnam P (2006) Changes in the velocity structure of the Greenland ice sheet. Science, 311(5763), 986-990 (doi: 10.1126/science.1121381)

Rignot E, Fenty I, Menemenlis D and Xu Y (2012) Spreading of warm ocean waters around Greenland as a possible cause for glacier acceleration. Ann. Glaciol., 53(60), 257-266 (doi: 10.3189/ 2012AoG60A136)

Rignot E, Fenty I, Xu Y, Cai C and Kemp C (2015) Undercutting of marine-terminating glaciers in West Greenland. Geophys. Res. Lett., 42(14), 5909-5917 (doi: 10.1002/2015gl064236)

Sciascia R, Straneo F, Cenedese C and Heimbach P (2013) Seasonal variability of submarine melt rate and circulation in an East Greenland fjord. J. Geophys. Res.-Oceans, 118(5), 2492-2506 (doi: 10.1002/jgrc.20142)

Sciascia R, Cenedese C, Nicoli D, Heimbach P and Straneo F (2014) Impact of periodic intermediary flows on submarine melting of a Greenland glacier. J. Geophys. Res.-Oceans, 119, 7078-7098 (doi: 10.1002/2014JC009953)

Seale A, Christoffersen P, Mugford R and O'Leary M (2011) Ocean forcing of the Greenland ice sheet: calving fronts and patterns of retreat identified by automatic satellite monitoring of eastern outlet glaciers. J. Geophys. Res.-Earth Surf., 116, F03013 (doi: 10.1029/2010jf001847)

Slater D, Nienow P, Cowton T, Goldberg D and Sole A (2015) Effect of near-terminus subglacial hydrology on tidewater glacier 
submarine melt rates. Geophys. Res. Lett., 42(8), 2861-2868 (doi: 10.1002/2014gl062494)

Sole A and 6 others (2011) Seasonal speedup of a Greenland marineterminating outlet glacier forced by surface melt-induced changes in subglacial hydrology. J. Geophys. Res.-Earth Surf., 116, F03014 (doi: 10.1029/2010jf001948)

Straneo F and Cenedese C (2015) The dynamics of Greenland's glacial fjords and their role in climate. Ann. Rev. Marine Sci., 7, 1-24 (doi: 10.1146/annurev-marine-010213-135133)

Straneo F and Heimbach P (2013) North Atlantic warming and the retreat of Greenland's outlet glaciers. Nature, 504(7478), 3643 (doi: 10.1038/nature12854)

Straneo F and 7 others (2010) Rapid circulation of warm subtropical waters in a major glacial fjord in East Greenland. Nat. Geosci., 3 (3), 182-186 (doi: 10.1038/ngeo764)

Straneo F and 6 others (2011) Impact of fjord dynamics and glacial runoff on the circulation near Helheim Glacier. Nat. Geosci., 4 (5), 322-327 (doi: 10.1038/ngeo1109)

Straneo F and 8 others (2012) Characteristics of ocean waters reaching Greenland's glaciers. Ann. Glaciol., 53(60), 202-210 (doi: 10.3189/2012AoG60A059)

Straneo F and 15 others (2013) Challenges to understanding the dynamic response of Greenland's marine terminating glaciers to oceanic and atmospheric forcing. Bull. Am. Meteorol. Soc. 94(8), 1131-1144 (doi: 10.1175/bams-d-12-00100.1)

Sutherland D and Straneo F (2012) Estimating ocean heat transports and submarine melt rates in Sermilik Fjord, Greenland, using lowered acoustic Doppler current profiler (LADCP) velocity profiles. Ann. Glaciol., 53(60), 50-58 (doi: 10.3189/2012AoG60A050)

Sutherland D, Straneo F and Pickart R (2014) Characteristics and dynamics of two major Greenland glacial fjords. J. Geophys. Res.Oceans, 119(6), 3767-3791 (doi: 10.1002/2013jc009786)

Syvitski J, Andrews J and Dowdeswell J (1996) Sediment deposition in an iceberg-dominated glacimarine environment, East Greenland: Basin fill implications. Glob. Planet. Change, 12(14), 251-270 (doi: 10.1016/0921-8181(95)00023-2)

Xu Y, Rignot E, Menemenlis D and Koppes M (2012) Numerical experiments on subaqueous melting of Greenland tidewater glaciers in response to ocean warming and enhanced subglacial discharge. Ann. Glaciol., 53(60), 229-234 (doi: 10.3189/ 2012AoG60A139)

Xu Y, Rignot E, Fenty I, Menemenlis D and Flexas M (2013) Subaqueous melting of Store Glacier, west Greenland from three-dimensional, high-resolution numerical modeling and ocean observations. Geophys. Res. Lett., 40(17), 4648-4653 (doi: 10.1002/grl.50825)

MS received 11 May 2016 and accepted in revised form 15 September 2016; first published online 5 October 2016 